\title{
Interactive comment on "Holistic monitoring of increased pollutant loading and its impact on the environmental condition of a coastal lagoon with Ammonia as a proxy for impact on biodiversity" by Areen Sen and Punyasloke Bhadury
}

Areen Sen and Punyasloke Bhadury

pbhadury@gmail.com

Received and published: 24 March 2017

Reply to Anonymous Referee \#2 The authors would first like to thank the referee for painstakingly going through the entire manuscript and giving valuable comments on the work. The comments and suggestions provided by the reviewer have significantly helped in improving the overall quality of the manuscript.

Printer-friendly version

1. Despite it made an interesting reading, the study suffers from various shortcomings without any conclusive cause/effect output.

Discussion paper

The authors have taken the points into consideration. In order to make the work conclu- 
sive the title has been thus reworked to "Hollistic monitoring of environmental condition of a coastal lagoon with Ammonia as a proxy for sedimentary carbon content" in revised version of the manuscript. The objective of the work has also been reframed and the conclusion has also been reframed in revised version of the manuscript.

2. Heavy metal pollution in Chilika Lagoon doesn't appear to be intense (no major industries / point sources cited by the authors) nor there is any abnormal level of metallic ions. This aspect appears out of context considering the main objective of this study is to investigate the effects of nutrient loading on the sedimentary organic carbon vis-á-vis the foraminiferal Ammonia sp. distribution and abundance.

The referee has rightly pointed out that heavy metal pollution in Chilika lagoon is not intense and that this aspect of the previous version was out of context with reference to the objective. In the revised version all methodologies, results and discussions pertaining to heavy metals or potentially toxic elements (PTEs) have been removed.

3. The investigation was held for a year at monthly intervals at six selected stations representing organically rich areas and those unaffected by human inhabitation being away. In the process, it is not however clear why the northern part of the lagoon (where many rivers open, Fig.1; line 38; lines 549-551) was not considered by the authors; one or two locations there would have been meaningful.

The authors designed the present six stations after observing the benthic biota of the entire lagoon by performing monthly samplings from June 2013 across twenty three sampling stations. In the revised version of manuscript the criterion for selecting the studied stations has been detailed.

5. Descriptions of seasonal variations of environmental variables though thorough could not be used to relate seasonality of Ammonia sp. I am not sure even the authors are clear on this. In such a case why elaborate descriptions on how each of these (nutrient) variables changed with season? This component could be shortened.

Printer-friendly version

Discussion paper

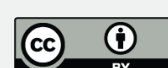


The authors would like to state that the objective of the work is not to investigate the seasonality of Ammonia, but to provide a holistic view of the lagoon environment with respect to possible nutrient load and its impact on sedimentary condition. The role of Ammonia in the work is only as a proxy for increased carbon load in the sediment. The authors have reframed the objective in revised version of manuscript to better represent that idea. Seasonality of Ammonia from the lagoon has already been studied previously by us and the reference has been included in revised version of manuscript. Descriptions on seasonal variations of nutrients is thus not to link with Ammonia, but rather to provide a holistic idea of the environmental condition.

6. Looking at the nutrient features, it is not clear entirely whether Chilika Lagoon is highly eutrophic. The low N: Si ratio found during the study (and therefore abundance of diatoms instead of cyanobacteria; vide Srichandran et al., 2015 cited by the authors) is suggestive of near healthy conditions in the lagoon contrary to what the authors report. It is a bit confusing therefore. No cyanobacterial blooms and only bacillariophyceans in moderate proportions, is a good sign!

The authors would like to thank the referee for pointing out this issue. In the revised version of manuscript the seasonal observation of $\mathrm{N}: \mathrm{Si}>1$ in the northern and central part of the lagoon has been clearly mentioned. Previous reports of seasonal dominance of different cyanobacterial genera corresponding to this seasonal change in $\mathrm{N}$ :Si have also been included in the revised manuscript. The seasonal dominance of cyanobacterial genera corresponding to $\mathrm{N}$ :Si values $>1$ does indicate towards an eutrophic condition. A recent investigation reporting the eutrophic nature of the lagoon has also been included in revised version of the manuscript.

7. What Is the role of seagrasses, if any, in the lagoon? Are there seagrass beds at the selected sites?

The authors would like to state that no seagrass beds were observed during the study period at any of the sites selected as part of this study.

Printer-friendly version

Discussion paper 
8. Discrepancies are noticed with respect to the distribution of TOC. The highest values at st.C5 as reported by the authors do not conform to river inputs since there are no rivers shown close to the location (see Fig.1).

In the revised version of manuscript we have detailed the station description for CS5 and we have detailed Fig. 1 to better represent the opening of riverine flow in the station.

9. Coming to the biological aspects, it is not clear why only the top $2 \mathrm{~cm}$ of sediment were considered for extracting the fauna; this could be one of the reasons for the overall paucity of Ammonia numerically at the selected sites. Genus Ammonia is known to inhabit organically rich sediments globally often with mono specific dominance overwhelming all other meiobenthos. The present findings (paucity of fauna) are contrary to this, not fully explained by the authors. Whether the organic rich sediments are potentially liable to dissolve calcareous tests, should not be forgotten.

The choice to restrict to the surface fraction was made following the finding of Sen and Bhadury (2016) where $>90 \%$ of the living assemblage was found to be residing in the surface $2 \mathrm{~cm}$, which has been included in revised manuscript. The paucity of Ammonia has also been discussed in depth by Sen and Bhadury (2016). The authors would like to thank the referee for potential dissolution of calcareous tests under organic rich environments. The point has now been discussed in revised version of manuscript.

10. Based on Bray-Curtis similarity, the samples could be divided into 6 clusters, which however showed no specific spatial and/or seasonal variability except that some had only dead shells while others a mixture of live/dead shells in varying proportions. Characterization of either area(s) or season could not be demonstrated therefore. This could be because of lack of adequate number of replicates for a given location/region. It is however interesting the correlation between surface (not pore water) NO3 and sediment TOC was significant. In ecological parlance, correlation coefficients R2 0.5 (P _0.05) are usually the confident levels of acceptance of any existing relationship be-

Printer-friendly version

Discussion paper 
tween the biota and environmental factors.

In the revised version of manuscript, the authors have thoroughly discussed the presence of spatial clustering. The authors would like to thank the referee for pointing out the confidence levels of acceptance of existing relationships investigated by correlation analysis. In the revised version of manuscript the same confidence level has been used and mentioned in each case.

11. The ms needs to be checked for typos, grammatical corrections and phrasing. At one place (line 126), it is written 'subtropical'. Chilika lagoon is situated on the Indian seacoast well within $23.50 \mathrm{~N}$ latitude.

The authors have taken utmost care to minimize typographical, grammatical and phrasing errors in the revised manuscript. The mention of Chilika lagoon as 'subtropical' previous version was indeed a typographical error and has been rectified in revised version of manuscript.

Interactive comment on Biogeosciences Discuss., doi:10.5194/bg-2017-13, 2017. 